\title{
Production Cycle for Large Scale Fission Mo-99 Separation by the Processing of Irradiated LEU Uranium Silicide Fuel Element Targets
}

\author{
Abdel-Hadi Ali Sameh \\ Zellmarkstraße 7, 76275 Ettlingen, Germany \\ Correspondence should be addressed to Abdel-Hadi Ali Sameh; a.a.sameh@gmx.de
}

Received 16 June 2013; Accepted 20 July 2013

Academic Editor: Mushtaq Ahmad

Copyright (C) 2013 Abdel-Hadi Ali Sameh. This is an open access article distributed under the Creative Commons Attribution License, which permits unrestricted use, distribution, and reproduction in any medium, provided the original work is properly cited.

\begin{abstract}
Uranium silicide fuels proved over decades their exceptional qualification for the operation of higher flux material testing reactors with LEU elements. The application of such fuels as target materials, particularly for the large scale fission Mo-99 producers, offers an efficient and economical solution for the related facilities. The realization of such aim demands the introduction of a suitable dissolution process for the applied $\mathrm{U}_{3} \mathrm{Si}_{2}$ compound. Excellent results are achieved by the oxidizing dissolution of the fuel meat in hydrofluoric acid at room temperature. The resulting solution is directly behind added to an over stoichiometric amount of potassium hydroxide solution. Uranium and the bulk of fission products are precipitated together with the transuranium compounds. The filtrate contains the molybdenum and the soluble fission product species. It is further treated similar to the in-full scale proven $\mathrm{UAl}_{x}$ process. The generated off gas stream is handled also as experienced before after passing through $\mathrm{KOH}$ washing solution. The generated alkaline fluoride containing waste solution is noncorrosive. Nevertheless fluoride can be selectively bonded as in soluble $\mathrm{CaF}_{2}$ by addition of a mixture of solid calcium hydroxide calcium carbonate to the sand cement mixture used for waste solidification. The generated elevated amounts of LEU remnants can be recycled and retargeted. The related technology permits the minimization of the generated fuel waste, saving environment, and improving processing economy.
\end{abstract}

\section{Introduction}

Particularly for the large scale producers, the conversion of the production targets for fission Mo-99 presents a serious challenge for keeping economical conditions for operating their plants. The uranium enrichment dropping from $\sim 90 \%$ to $\sim 19.8 \%$ demands modifications on process operation to compensate for the resulting loss in output. Evaluations based on keeping the production process proven since decades unchanged and just increasing the amount of processed targets are not realistic in general. The dominant reasons are limitations on efficient irradiation positions in the available research reactors plus drastically increased processing and waste costs.

The idea of maintaining the current production process [1-8] by increasing fuel densities of the targets exploiting the progress in target technology from actually $\sim 1 \mathrm{gU} / \mathrm{cm}^{3}$ for highly enriched uranium (HEU) to approximately $2.6 \mathrm{gU} / \mathrm{cm}^{3}$ for low enriched uranium (LEU) targets can be classified as a compromise. Such compromise is appropriate for several small- and medium-scale facilities but not for large scale producers of batch sizes in the average of $4000 \mathrm{Ci}$ of Mo-99 at End of Production (EOP). When keeping the same amount of targets, the predictable loss of produced activity will be-under optimal conditions-more than $30 \%$. The described drawback can be prevented by applying LEU targets of factor 5 higher fuel contents than the actual HEUbased targets. Actually, that condition can be fulfilled by two types of targets. One of them is made from U-metal foil tightly enclosed in aluminum. The dissolution process related to these targets is applying nitric acid, respectively, low basic carbonate solution and anodic oxidation of uranium [9-11]. The other target is manufactured from uranium silicide fuel cladded with aluminum, derived from the MTR type fuel 
developed for research reactor core conversions. Dissolution experiments of $\mathrm{U}_{3} \mathrm{Si}_{2}$ in alkaline media by $\mathrm{H}_{2} \mathrm{O}_{2}$ [12-15] showed promising results on small scale productions which could not be confirmed in larger scale. Main reason for that lack of larger scale is the aggressive decomposition of $\mathrm{H}_{2} \mathrm{O}_{2}$ in presence of the alloy. With respect to the experienced problem, the process presented below follows another concept.

The publication has focused on the processing of irradiated LEU targets of uranium silicide for the large scale production of fission Mo-99. Silicide targets were favored because of their proven and reliable operation as research reactor fuels during decades and their commercial availability on the world market. Moreover, the results achieved with the presented dissolution process [15-20] favored that selection. As the silicide compound is not attacked by caustic solution applied for the target digestion, a selective dissolution process for the remaining silicide meat had to be developed. Evident condition was and still is that the new process steps are fitting to the proven HEU-based production process operating with $\mathrm{UAl}_{x}$-Al targets from HEU. Originally the up-to-date process was developed and operated at KFK as an integral part of a closed cycle. Figure 1 shows the scheme of the $\mathrm{UAl}_{x}$ production cycle.

The part of that process related to the Mo-99 separation and the off-gas handling technology is actually operated at the Mallinckrodt Medical Facility at Petten, The Netherlands. Figure 2 shows a simplified scheme of the process operating at Petten. It was established there by a licensing and know-how transfer agreement contracted with KFK. The Petten facility is producing approximately $25 \%$ of the world market which is estimated to be $12,000 \mathrm{Ci} 6$ days precalibrated weekly. The operation reliability and the environmental impact of this installation are exceptional worldwide with an average annual release of $7.3 \times 10^{11} \mathrm{~Bq}$ of Xe-133. All data mentioned above were investigated, respectively, determined by the CTBTO and published by PNNL [21].

Already during the development and testing at KFK, implementation of the silicide fuel and related modifications of the original $\left(\mathrm{UAl}_{x}\right)$ process had to fit to the proven process concept. At KFK, the investigation program was successfully completed and the process modifications were demonstrated, with both fitting to a later scale of 1,000 6d-Ci Mo-99 at EOP. Keeping the proven concept, the new process has been integrated in a closed fuel cycle. That cycle was demonstrated repeatedly. The Mo-99 separation process is started by alkaline digestion of the irradiated silicide targets. The remaining silicide residue is dissolved in hydrofluoric acid under oxidizing conditions [22, 23].

\section{Considerations on Processing Operation}

\subsection{Uranium Silicide as Target Compound}

(i) Processing of irradiated silicide fuels permits the adaptation of major parts of the original HEU process for the production of fission Mo-99 from irradiated $\mathrm{UAl}_{x}$ targets. The selection of $\mathrm{U}_{3} \mathrm{Si}_{2}$ as the fuel compound for the LEU targets had the same background as had the choice of $\mathrm{UAl}_{x}$ as the fuel compound for the HEU fuel. Both selected target types presented just the adaptation of the type of research reactor fuel throughout applied for the related U-enrichment, resulting in $\mathrm{UAl}_{x}$-based targets for $\mathrm{HEU}$ and $\mathrm{U}_{3} \mathrm{Si}_{2}$ based for LEU.

(ii) Since some decades, silicide-based fuel elements are presenting the standard nuclear fuels for high and medium flux material test reactors (MTRs). That fuel combines high fuel density with high thermal and dimensional stability and provides operations safety up to burn up of around $80 \%[15,17,19]$.

(iii) Already the regularly applied standard uranium density of $\mathrm{U}_{3} \mathrm{Si}_{2}$ fuel of $4.8 \mathrm{gU} / \mathrm{cm}^{3}$ permits full compensation of the uranium content originating from the conversion from HEU to LEU, for fuel elements as well as for irradiation targets.

(iv) Cladding material and dimensions of the $\mathrm{U}_{3} \mathrm{Si}_{2}$-based LEU targets are very similar to the processed $\mathrm{UAl}_{x}$ based HEU targets. That fact prevents expensive modifications of the proven hardware devices used for carrying out the reactor irradiations and handling the production targets in hot cells.

(v) The potential of silicide fuels enables the production of fuel elements and irradiation targets of even higher U-densities, up to $5.8 \mathrm{gU} / \mathrm{cm}^{3}$. Such fuels were produced from the same named compound and were also successfully irradiated to average burn-ups of above $50 \%$ without any deviation in their dimensional and thermal stability [18-20]. The potential for higher Uloading is of relevance with respect to future recycling of the uranium from spent targets and retargeting of the purified fissionable material.

(vi) From economic point of view, recycling and retargeting are essential, particularly for large scale producers.

2.2. Evaluations of Dissolution Process. The dissolution of the short-time cooled irradiated targets presents a sensitive operation step regarding the high inventory of volatile and radio-toxic fission nuclides contained in the fuel matrix (meat). Operational safety and public acceptance concerns demand the minimization of the potential contamination as well as hazards from emissions of volatile fission products into the environment. Most efficient precaution measure is the implementation of advanced processing and off-gas handling technologies. Both measures are interacting with each other. Essential precondition for the minimized release of iodine is the exclusion of any acidic operation as long as iodine activity is in the system. Another concern is related to elevated releases of the isotopes $\mathrm{Xe}-133$ and $\mathrm{Xe}-135$ to the environment. The most efficient and economical way of handling those issues is applying a combination of advanced process operation technology and efficient xenon retention, respectively, delay on charcoal columns. For safety reasons, any application of charcoal filters is strictly prohibiting the presence of nitrogen oxide in the off-gas stream. Thus, any dissolution of irradiated fuel in nitric acid would be most critical as nitric acid is always accompanied by $\mathrm{NO}_{2}$ 


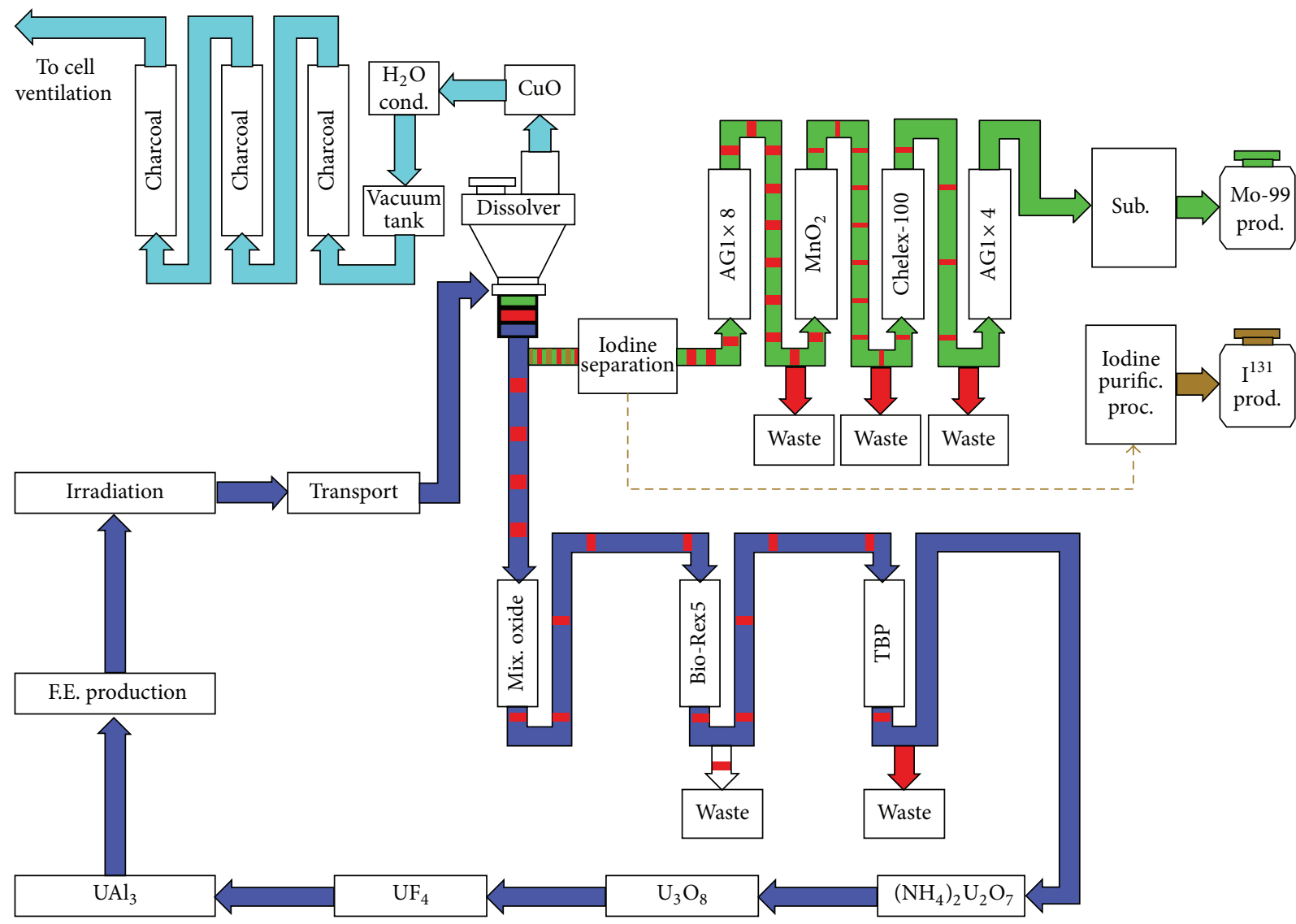

FIGURE 1: Production cycle of HEU-based $\mathrm{UAl}_{x}$ - plate-type targets.

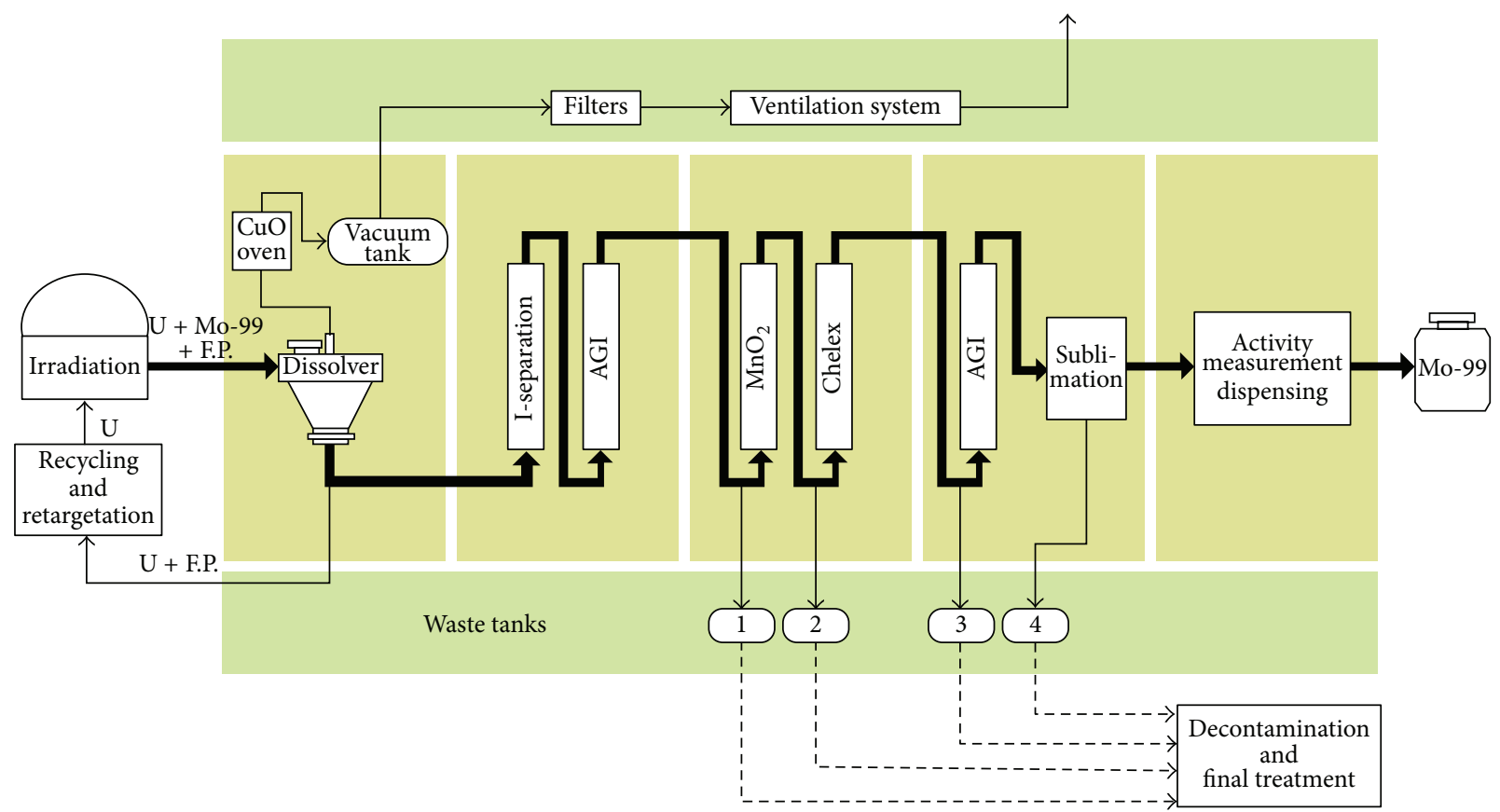

FIGURE 2: Schemes of the HEU-based fission Mo-99 production process from irradiated $\mathrm{UAl}_{x}$ targets. 
permanently generated during such operation by radiation degradation of $\mathrm{HNO}_{3}$.

The described drawbacks are major reasons for a strong preference for the alkaline processing starting by the alkaline digestion of the target. The digestion is fully sufficient to get the molybdenum into solution as it is attacking the aluminide compound. Subsequently the silicide is dissolved by an oxidizing acid treatment at room temperature. The selected solvent HF is proved to be efficient as well as excellent to handle by using related proven materials inside the hot cell such as Hastelloy. Hastelloy has been applied for the production of hundreds of tons of HF per year by chemical industry. The described drawbacks of applying $\mathrm{HNO}_{3}$ accompanied by its degradation products are prevented by the KFKdeveloped processing system. As $\mathrm{HF}$ is one of the most resistant chemicals, it is not decomposing by radiation and it is excellent to be washed out of the off-gas stream by passing through a solution of $\mathrm{KOH}$. The dissolution process is carried out at room temperature within 60 minutes. In the subsequent purification process the acidic solution has not to be handled as it is converted to alkaline after the dissolution step. Fluoride anions in the alkaline solution are neither corrosive nor disturbing the following purification of the product stream. Further, fluoride anions in the alkaline media are not disturbing the Mo-retention on the anion exchanger AG1 (see Figures 1 and 2). Nitrates as added by some producers to the digesting solution are the blocking highly efficient and economical purification systems such as AG1 and Chelex-100. To prevent hydrogen formation during the alkaline digestion step of the aluminum alloy of the target cladding and the $\mathrm{UAl}_{x}$ meat, in some processes, nitrate is added. The alternative hydrogen oxidation to water on copper oxide as applied at KFK never created any problem with all users. For the described reasons all large scale producers including the Petten facility never added nitrate to the caustic solution. A final aspect of the KFK designed and developed processing is related to the waste treatment. For the silicide process the alkaline waste stream is solidified in cement similar to the comparable $\mathrm{UAl}_{x}$ process. In case of the silicide dissolution, the fluoride content in the alkaline solution iswith solid mixture of $\mathrm{Ca}(\mathrm{OH})_{2}$ and $\mathrm{CaCO}_{3}$ added to the cement-forming insoluble $\mathrm{CaF}_{2}$.

Back to the dissolution part of the processing, both the digestion of the target and the subsequent HF-dissolution step are operated in a Hastelloy dissolver. The filtration unit connected to the dissolver is also made from Hastelloy. The Mo-separation process is started by the alkaline digestion of the aluminum cladding (preferably "AlMgl") together with Al-matrix of the meat, the fueled part of the target, in $6 \mathrm{M} \mathrm{KOH}$. Aluminum and the fission products located at the surface of the insoluble silicide particles are dissolved. These are mainly cesium, strontium, iodine, molybdenum, and small contaminations of other fission products such as lanthanides, ruthenium, and zirconium. The off-gas of the alkaline digestion contains hydrogen generated by the aluminum dissolution to aluminate and the magnesium conversion to the hydroxide together with approx. $10 \%$ of the noble gas activity. The major radioactivity of the gas stream is originating from $\mathrm{Xe}-133$ and $\mathrm{Xe}-135$. The noble gases leave the dissolver together with the hydrogen at its upper end, driven by helium or nitrogen gas which is constantly metered into the dissolver. Hydrogen is oxidized to water via a copper oxide "oven." That oven is a heated device containing $\mathrm{CuO}$. The formed water steam is condensed in a related device. Xenon is collected together with the driving gas in preevacuated stainless steel tanks and pumped into a xenon delay section later on passing cooled deep bed carbon filters on its way. The described operation, which is similar to the $\mathrm{UAl}_{x}$ digestion, is schematically presented in Figure 3.

The filtrate of the alkaline digestion contains approx. $10 \%$ of the Mo-99 generated by fission together with the related soluble fission-generated nuclides. To collect the included Mo-activity the filtrate is undergoing the same purification procedure as the molybdenum bulk later on. Therefore the filtrate is fed through a floating silver oxide column where iodine is retained. Figure 4 is showing a simplified scheme of the iodine separation on this advanced system. The named column is located above a stainless steel (SS) device provided with a filtration and collecting unit. The column is connected with the device below by an SS-valve. That valve to the vessel is closed during feeding the process solution. After ending loading of the iodine containing solution the valve to the vessel is opened. The floating silver oxide is washed into the vessel. The collected silver oxide is reduced to silver by a solution of $\mathrm{H}_{2} \mathrm{O}_{2}$. The previously retained iodine remains loaded over silver metal as silver iodide. It can be stored for safe iodine decay or further used for the separation of I-131 on commercial base.

The passing through solution which contains the Moactivity is loaded on the strongly basic anion exchanger AG1. The operation step described in the previous section is repeated with the alkaline bulk resulting from the silicide dissolution. The Mo-bulk is also fed through the same AGl column after completion of the above described iodine separation step on silver oxide. The eluate of AG1 contains the combined two Mo-streams. In order to improve the purification efficiency and to reduce the amount of higher active solid waste, the AG1 operation is split into two AG1 columns connected and acting behind each other. The first AG1 is made of stainless steel and the second being a larger column is of propylene (PP). As experienced, contaminants (on top of all iodine) and soluble ruthenate compounds reduced to ruthenium dioxide on the organic resin are retained at the entering side on the first column. Molybdenum is moved by the alkaline process solution and the following washing $\mathrm{KOH}$ solution through the first column to the second and larger column connected behind. After disconnecting of the first column being loaded with contaminants, the elution of molybdenum from that second column is initiated. With respect to the minimization of higher active waste, the small column is made of stainless steel to permit long-term radiation resistant storage of the tightly enclosed contaminants. The larger column behind is of PP. It is cheaper to purchase and far more economical to treat as waste. The experience achieved with this modification is highly positive from all sides. The same concept is applied by the final AG1 system (see Figure 2) as the potential contamination hazard is very low. Here the entering small column is of PP already. 


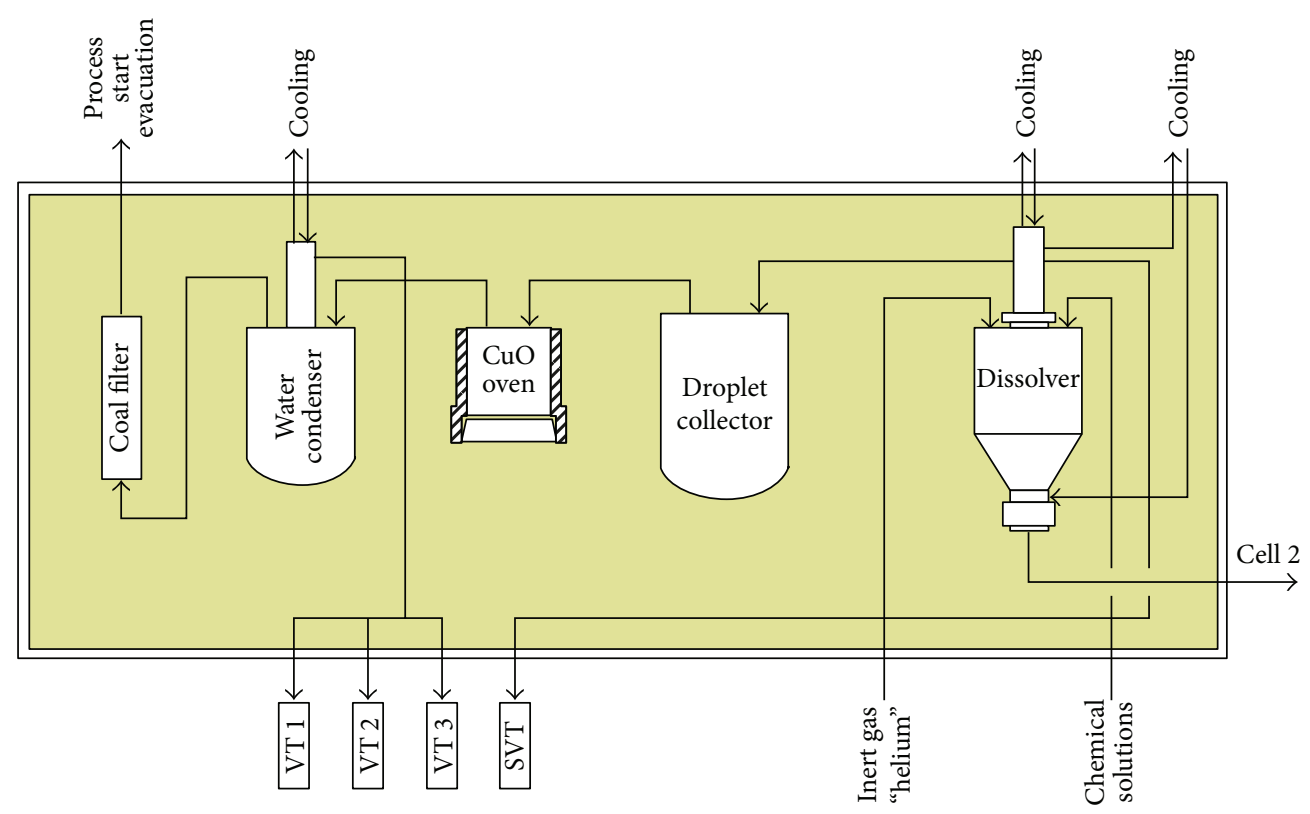

FIgURE 3: Treatment of the off-gas generated during alkaline digestion of $\mathrm{U}_{3} \mathrm{Si}_{2}$ and AlMg1-cladding.

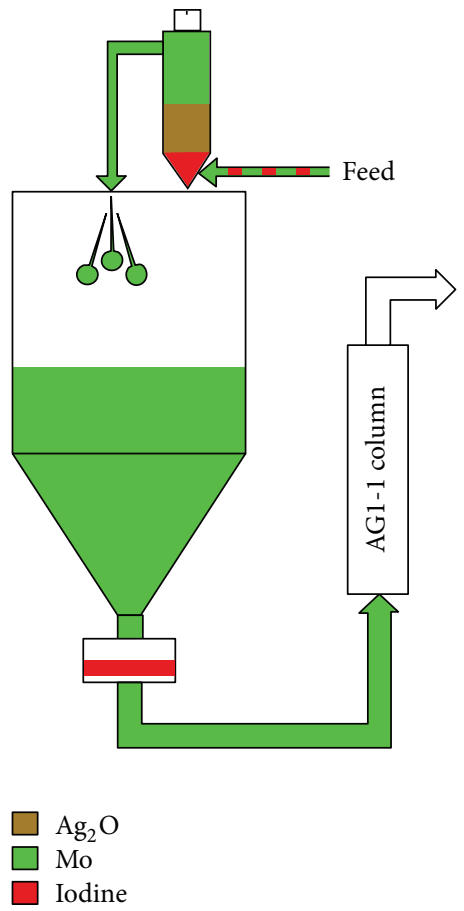

FIGURE 4: Separation of iodine on the floating silver oxide column.

2.3. Dissolution of Silicide Meat in $\mathrm{HF} / \mathrm{H}_{2} \mathrm{O}_{2}$. The silicide particles of the meat remaining on the sinter metal filter are dissolved in $\sim 6 \mathrm{M}$ HF under catalyzed oxidation conditions [23]. The oxidation agent is hydrogen peroxide. Suitable catalytic agents are $\mathrm{KI}, \mathrm{KBr}$, and $\mathrm{KCl}$ or higher oxidation states of halogen compounds such as hypochlorite, hypobromite, or $\mathrm{KIO}_{3}$. The dissolution is carried out at $\sim 20^{\circ} \mathrm{C}$. The oxidation agent is needed to oxidize the primary formed insoluble layer of $\mathrm{UF}_{4}$ to soluble $\mathrm{UO}_{2} \mathrm{~F}_{2}$. The oxidation with $\mathrm{H}_{2} \mathrm{O}_{2}$ in absence of the catalyzing agent is inefficient because a major amount of the $\mathrm{H}_{2} \mathrm{O}_{2}$ is just decomposed without significant impact. Fully different is the situation in presence of the mentioned halide compounds. All these compounds are oxidized by $\mathrm{H}_{2} \mathrm{O}_{2}$ which acts as strong oxidizing agent in acidic solutions. The following formula and the related redox potentials underline the oxidation efficiency of hydrogen peroxide in acidic media.

Redox potentials of $\mathrm{H}_{2} \mathrm{O}_{2}$ and related catalysing compounds used for the oxidation of $\mathrm{U}^{\mathrm{IV}}$ to $\mathrm{U}^{\mathrm{VI}}$ and its solution in hydrofluoric acid:

$$
\begin{gathered}
\mathrm{U}^{4+}+2 \mathrm{H}_{2} \mathrm{O} \leftrightarrows \mathrm{UO}_{2}^{2+}+4 \mathrm{H}^{+}+2 \mathrm{e}+0.338 \mathrm{~V} \\
\mathrm{H}_{2} \mathrm{O}_{2}+2 \mathrm{H}^{+}+2 \mathrm{e} \leftrightarrows 2 \mathrm{H}_{2} \mathrm{O}+1.77 \mathrm{~V} \\
\mathrm{Cl}^{-}+\mathrm{H}_{2} \mathrm{O} \leftrightarrows \mathrm{HClO}+\mathrm{H}^{+}+2 \mathrm{e}+1.50 \mathrm{~V} \\
\mathrm{Br}^{-}+\mathrm{H}_{2} \mathrm{O} \leftrightarrows \mathrm{HBrO}+\mathrm{H}^{+}+2 \mathrm{e}+1.33 \mathrm{~V} \\
\mathrm{I}^{-}+\mathrm{H}_{2} \mathrm{O} \leftrightarrows \mathrm{HIO}+\mathrm{H}^{+}+2 \mathrm{e}+0.99 \mathrm{~V}
\end{gathered}
$$

The oxidized halogen compounds oxidize efficiently UF4 to soluble $\mathrm{UO}_{2} \mathrm{~F}_{2}$ following the chemical formula:

$$
\mathrm{UF}_{4}+\mathrm{HIO} \longrightarrow \mathrm{UO}_{2} \mathrm{~F}_{2}+\mathrm{HI}+2 \mathrm{HF}
$$

The complete dissolution formula for the silicide alloy is

$$
\mathrm{U}_{3} \mathrm{Si}_{2}+18 \mathrm{HF}+6 \mathrm{H}_{2} \mathrm{O}_{2} \longrightarrow 3 \mathrm{UO}_{2} \mathrm{~F}_{2}+2 \mathrm{H}_{2} \mathrm{SiF}_{6}+6 \mathrm{H}_{2}
$$

Following the formula, 18 moles of HF is needed for the dissolution of $768.5 \mathrm{~g}$ of the alloy. A full scale production of about $4,000 \mathrm{Ci}$ at EOP demands around $200 \mathrm{~g}$ of $19.75 \%$ 
enriched $\mathrm{U}_{3} \mathrm{Si}_{2}$, assuming similar irradiation conditions as applied for an equivalent amount of HEU, 93\% enriched. The dissolution of the HEU-related amount demands far less hydrofluoric acid.

The dissolution of the silicide is completed within $\sim 60$ minutes. The solution is pressed through the sinter metal filter and fed in to an over stoichiometric amount of $\sim 8 \mathrm{M}$ $\mathrm{KOH}$ solution. The $\mathrm{KOH}$ excess is adjusted to a final total molarity of $\sim 3 \mathrm{M} \mathrm{KOH}$. Uranium is precipitated as potassium uranate together with the insoluble hydroxides and oxide hydrates of the related fission products and higher actinides. The alkaline filtrate contains all in the fuel still remaining Mo-99 activity. This amount presents $90 \%$ of the in total by fission generated Mo-99 activity. The solution also contains the related soluble fission products iodine, cesium, partially strontium, and contaminants of further fission products, mainly ruthenium and antimony.

The above described HF treatment is operated in Hastelloy devices. Also the acidic filtrate is fed through a Hastelloy pipe in to the precipitation vessel, below the surface of the $\mathrm{KOH}$ solution. All tubes used for feeding the acidic solution are treated behind with alkaline solution. All operations under alkaline conditions are carried out in stainless steel devices.

The uranium precipitate is boiled for 20 minutes to insure the decomposition of the formed soluble peroxide compounds of uranium. The Mo-containing filtrate is fed through the floating silver oxide column as described before (see Figure 4). The filtrate of the formed Ag/AgI_ precipitate is fed through the same AG1 column which the first $10 \%$ of generated Mo had been loaded on. The described operation and the specific treatment of the dissolver exhaust gases both during the HF operation [23] are schematically presented in Figure 5.

2.4. Elution of the AG1 Column. The loaded AG1 is washed by minimal 3-column volumes of $3 \mathrm{M} \mathrm{KOH}$ to ensure efficient replacement of the fluoride anions. The resin bed is emptied from residual amounts of the $\mathrm{KOH}$ solution by passing air through. The elution is initiated by a solution of $1 \mathrm{M} \mathrm{NaOH}$ and $2 \mathrm{M} \mathrm{NaNO}_{3}$. The solution is fed from the bottom to the top of the column to achieve optimal contact between eluent and resin. The introduction of nitric acid and nitrate ensures excellent elution yields for this operation. The positive influence of nitrate on the Mo-elution from AG1 turns to the negative for the subsequent purification step on Chelex-100. Thereto molybdenum is loaded on Chelex-100 from a reducing and complex forming media. Nitrate must be avoided in the whole system by loading of the cationic molybdenum compounds on a stationary phase, followed by washing out the $\mathrm{NO}_{3}{ }^{-} / \mathrm{HNO}_{3}$.

2.5. Mo-Loading on Hydrated $\mathrm{MnO}_{2}$ and Dissolution of the Loaded Matrix. The eluate of the AG1 column is acidified by $\mathrm{HNO}_{3}$ to a final acidity of $\sim 1$ molar. The adjusted Mo-solution is fed through a column of hydrated $\mathrm{MnO}_{2}$. Molybdenum is retained as cationic molybdenyl compound on the inorganic exchanger. The Mo-loaded stationary phase is washed with a solution containing $\sim 0.01 \mathrm{M} \mathrm{K}_{2} \mathrm{SO}_{4}$. The amount of the washing solution is adjusted such that the passing through solution is free of nitrate. The addition of $\mathrm{K}_{2} \mathrm{SO}_{4}$ is needed to stabilize the lattice of the $\mathrm{MnO}_{2}$ matrix by the larger potassium cation.

The introduction of the $\mathrm{MnO}_{2}$ column offers additional benefits on top off all the concentration of molybdenum and compact feed for the following purification step. The purified product is released from the column, free of losses by a unique operation [24]. Thereto the loaded matrix is directly dissolved in the feeding solution prior to the subsequent purification step on Chelex-100. The resulting solution consists of sulfuric acid, thiocyanate, sodium sulfite, and potassium iodide. The final molarity of the major compound is $\sim 2 \mathrm{M} \mathrm{H}_{2} \mathrm{SO}_{4}$. Under these conditions the molybdenum is reduced and forms the extremely stable anionic complex $\left[\mathrm{Mo}(\mathrm{SCN})_{6}\right]^{-3}$. The Mocomplex is retained on Chelex-100 with a distribution coefficient of about $5 \times 10^{4}$. In absence of the exchanger, Mocompounds of different oxidation stages below 6 are formed. In presence of the exchanger the equilibrium is moved to the complex of the highest negative charge. This compound is the red $\left[\mathrm{Mo}(\mathrm{SCN})_{6}\right]^{-3}$ complex. Higher Mo-oxidation stages have lower specific electrical charges. When the preferred compound is retained on the matrix, the dynamic equilibrium is moving in the described direction.

2.6. Purification on Chelex-100 Column. The purification of molybdenum on Chelex-100 offers outstanding decontamination efficiency [25].

This fact is underlined by the extremely high distribution coefficient for molybdenum thiocyanate compound on the resin of around $5 \times 10^{4}$, while the distribution coefficients of the related fission products species are in the average of 1 [4]. Most relevant for this part of operation are contaminations of lanthanides, ruthenium, and zirconium. The realized separation factors for the mentioned contaminations are $\sim 10^{4}$.

2.7. Final Chromatographic Purification on AG1 Column. The following operation is introduced as a preparatory step for the sublimation of MoVI oxide. The sublimation presents the ultimate purification of the product from organic and inorganic impurities.

Organic impurities are originating from flexible connecting tubes and applied organic exchangers. Such impurities present potential reducing agents and are the cause for lower elution yields of technetium from the generators at a later stage.

Inorganic impurity traces of iron, nickel, cobalt, and chromium are brought in the product solution by applied metallic hardware components. The presence of such impurities in the final product is the major reason for elevated breakthrough of molybdenum during loading and elution of the Tc-generator columns. Such phenomenon can be explained by the instability of the related cations under low acidic loading and almost neutral $\mathrm{pH}$-values during elution of the generators. The formed colloids in the solution adjusted for generator loading retain the molybdenum compounds on 


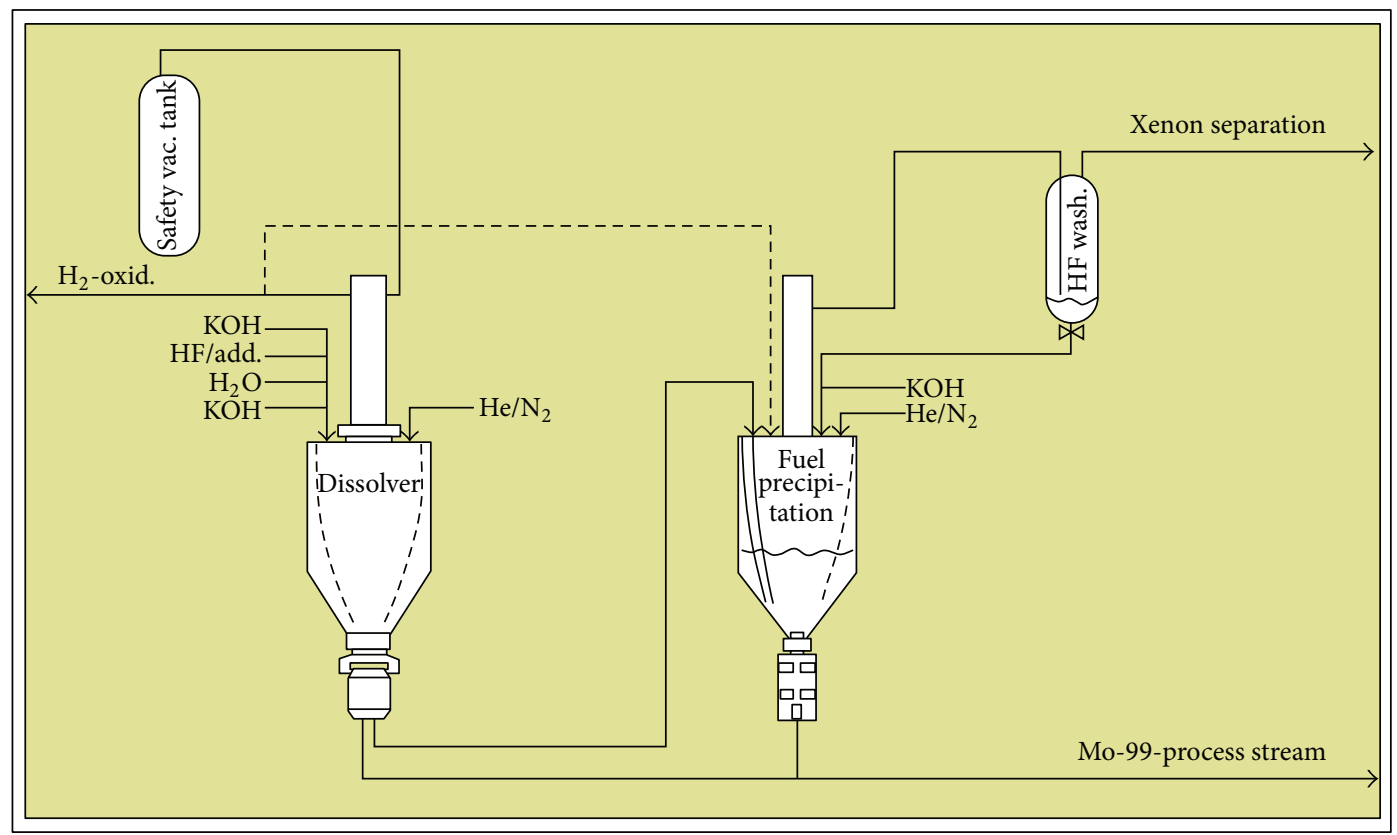

FIgURE 5: Combined operation of $\mathrm{U}_{3} \mathrm{Si}_{2}$ dissolution and precipitation.

their surface and pass, loaded with molybdenum, through the generator column.

The gradual thermal treatment of the dried product of up to $\sim 1,000^{\circ} \mathrm{C}$ at which the sublimation is completed decomposes the organic compounds and converts the inorganic impurities to the insoluble and chemically resistant so-called highly burned oxides. The oxides remain in the crucible while molybdenum oxide is sublimated. The resulting product shows excellent behavior during transportation of the bulk solution to the users and on the generators.

The sublimation step demands the preseparation of the major bulk of the cations, mainly of sodium from the Mocontaining solution. The presence of sodium in the Mosolution would lead to the formation of mixed oxides with molybdenum. The volatilization of MoVI-oxide from such compound demands for higher temperatures than salt-free systems. The purification of the Mo-solution is achieved by loading of molybdenum on an AG1 column. The stationary phase is washed by feeding of the sufficient amount of water through its resin bed.

The molybdenum elution is carried out by slow metering of highly pure 2-4 $\mathrm{M} \mathrm{HNO}_{3}$ through the column.

\subsection{Sublimation of MoVI-Oxide and Final Product Prepara-} tion. The nitric eluate is filled into a platinum/iridium crucible and evaporated to dryness. The operation is carried out in controlled ventilated quartz equipment. The acid vapor is driven out of the evaporation equipment by a metered nitrogen gas stream. The gas stream is directly fed through washing devices to prevent the contamination of the cell environment with acid and nitrogen oxide. After completed evaporation the crucible with the included dried MoVI-nitrate is placed in the quartz sublimation device. The complete unite is then placed into the sublimation oven. The temperature in the oven is gradually increased up to $\sim 1,000^{\circ} \mathrm{C}$. The sublimated Mo-oxide is collected in the quartz condenser above the crucible. The sublimation device is taken out of the oven for cooling in cell atmosphere. After a cooling time of $\sim 15 \mathrm{~min}$ the condensed Mo-oxide is dissolved in ammonia solution.

The Mo-solution is transferred into a round bottom flask. After adding a mixture of sodium hydroxide and sodium nitrate as calculated for the amount of final product, the ammonia is trapped out by smooth boiling. Both compounds are added to the final product solution to stabilize the molybdate in the high active solution and to prevent the precipitation of Mo-compounds of lower oxidation level, mainly consisting of hydrated $\mathrm{MoO}_{2}$. The addition of nitrate is also recommended to reduce the amount of hydrogen generated by radiation degradation of water in the product flask. The nitrate anions act as a radical catcher for hydrogen radicals, forming nitrite anions and water.

2.9. Recycling of Uranium from the Spent Fuel Residue. The uranium recycling process is initiated by dissolution and purification of the uranium stored in the collecting sinter metal filters. Those filters carry about $98 \%$ of the initially irradiated uranium as alkali uranate together with the insoluble fission products and the transuranium elements. The U-decontamination is carried out after an approximate cooling time of 6 months. During this period U-237 and the shorter living fission products have decayed. The remaining radiation dose of the residue is mainly caused by the fission product nuclides ruthenium, zirconium, niobium, and the lanthanides. The residue includes also the generated plutonium as oxide/oxide hydrate. The dissolution concept aims for the selective dissolution of uranium by keeping the bulk of the activity carriers and particularly plutonium in the residue. 
According to those considerations, a suitable process was developed and demonstrated at KFK [26]. The process is based on the basic dissolution of uranium by formation of the soluble anionic uranyl-tricarbonate complex $\left[\mathrm{UO}_{2}\left(\mathrm{CO}_{3}\right)_{3}\right]^{-4}$. The dissolution is carried out in hydrogen carbonate, carbonate, or mixed solutions of both. Hydrogen peroxide is added to the solution for the oxidation of $U$ species of lower oxidation stages potentially formed by radiation. The dissolution is carried out at temperatures between 20 and $40^{\circ} \mathrm{C}$. Figure 6 shows the dissolution behavior of ammonium diuranate as a function of $\mathrm{CO}_{3}{ }^{-2}$ concentration.

Figure 6 delivers the maximum uranium solubility of this system being at $48 \mathrm{gU} / \mathrm{L}$. For practical operation conditions a U-solubility of $40 \mathrm{gU} / \mathrm{L}$ should be considered. The limited solubility of uranium in the $\mathrm{HCO}_{3}{ }^{-} / \mathrm{CO}_{3}{ }^{-2}$ is by far overcompensated by the achieved advantages, which are as follows.

(i) Efficient decontamination of the uranium stream already by the dissolution process, in contradiction to the common fuel dissolution in nitric acid in which the uranium and nearly the whole contaminants are dissolved. The realized decontamination factors for uranium in the hydrogen-carbonate/carbonate system are in the average of 100 . The high separation efficiency also includes the decontamination from the generated transuranium elements neptunium and plutonium. Both are retained in the residue when the basic solution is boiled for 30 minutes.

(ii) Safe processing conditions, such as carbonate solutions being absolutely noncorrosive and requiring uncomplicated off-gas treatment measures only.

(iii) Quick and economical predecontamination of the uranium stream on compact, radiation resistant inorganic adsorbers.

2.10. Chromatographic Decontamination of the Uranium Tricarbonate Stream. In spite of the high decontamination of uranium by the carbonate dissolution, fission product carbonate ions are codissolved. Possibilities for their pre-separation on selective, radiation-resistant inorganic exchangers [26] were experimentally investigated. Static distribution experiments of the relevant fission nuclide ions on inorganic exchangers showed promising separation options for carbonate media. The preselected exchangers were further tested under dynamic conditions in absence-and later on also in presence-of uranium in the solution. The determined retention efficiencies of the relevant fission nuclides on the investigated exchangers are composed in Table 1 . The retention efficiencies of the related fission products on the different columns are expressed in \% of the original activity in the solution.

The data above show the efficiency of several inorganic exchangers for the separation of the investigated fission products in this system. Regarding these data, ruthenium is not completely retained on the related exchangers only. The successful adaptation of these promising systems under real process conditions depends on further information such as
TABLE 1: Dynamic retention behavior of fission product traces on inorganic exchanger columns: loading solution: $10 \mathrm{~mL}$, washing solution: $15 \mathrm{~mL}$, total $\mathrm{HCO}_{3}{ }^{-} / \mathrm{CO}_{3}{ }^{-2}$ content: $1 \mathrm{M}$, column diameter: $9.7 \mathrm{~mm}$, bed volume: $5.5 \mathrm{~mL}$, adsorber weight: $5 \mathrm{~g}$, loading speed: $30 \mathrm{cv} / \mathrm{h}$.

\begin{tabular}{lcccccc}
\hline Fiss. Prod. & Ce & Cs & $\mathrm{Ru}$ & $\mathrm{Sb}$ & $\mathrm{Sr}$ & $\mathrm{Zr}$ \\
\hline $\mathrm{Al}_{2} \mathrm{O}_{3}$ & 100 & 60 & 94 & 38 & 100 & 0 \\
$\mathrm{MnO}_{2}$ & 100 & 7 & 82 & 100 & 100 & 100 \\
$\mathrm{SnO}_{2}$ & 95 & 0 & 6 & 0 & 100 & 63 \\
\hline
\end{tabular}

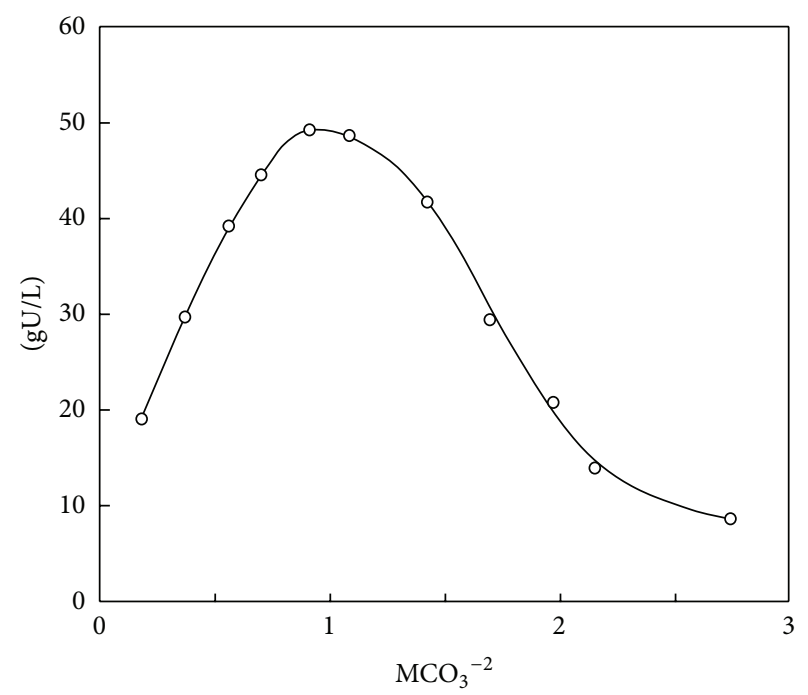

FIGURE 6: Dissolution of ammonium diuranate at varying $\mathrm{CO}_{3}{ }^{-2}$ concentrations.

the specific retention capacity of each nuclide in presence of uranium under real operation conditions.

Figure 7 shows the corresponding data for cerium on $\mathrm{MnO}_{2}$ as the stationary phase, Ce-141 being added as an indicator. The figure shows the high efficiency of hydrated $\mathrm{MnO}_{2}$ as a matrix for the chromatic separation of cerium from hydrogen-carbonate/carbonate containing solutions.

Comparable data were achieved for the other fission nuclides. All except ruthenium could be separated at one step on $\mathrm{MnO}_{2}$ columns. The deviating behavior of ruthenium is related to its ability to form varying complexes simultaneously. Even in presence of an adsorber retaining the preferred complex, the equilibrium adjustment is too slowly.

Interesting is the observed increase of the fission product retention in presence of uranium. The most probable explanation for this behavior is the decrease in concentration of free $\mathrm{HCO}_{3}{ }^{-} / \mathrm{CO}_{3}{ }^{-2}$ ions caused by the complex formation with uranium. Higher $\mathrm{HCO}_{3}{ }^{-} / \mathrm{CO}_{3}{ }^{-2}$ concentrations lead to the formation of negative charged fission product ions which are not retained on the adsorber. The reduced retention efficiency of ruthenium is also improved by the presence of uranium in the system but still remains lower than of all nuclides tested for the data of Table 1. Therefore additional purification steps are needed for the complete decontamination of the process stream from the rest activity of ruthenium remaining in the solution. The deviating behavior of ruthenium is also 


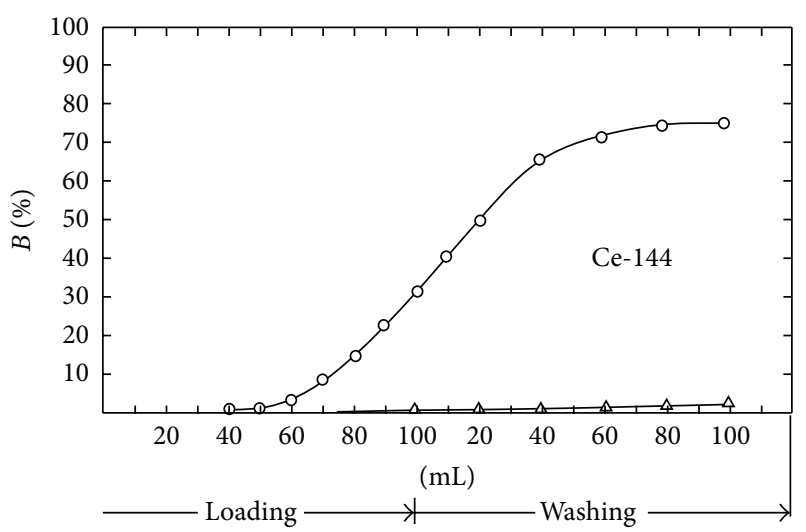

FIGURE 7: Breakthrough of cerium during the loading and washing on hydrated $\mathrm{MnO}_{2}$ column from hydrogen-carbonate/carbonate containing solution: $\mathrm{HCO}_{3}{ }^{-} / \mathrm{CO}_{3}{ }^{-2}$, ratio: $95 / 5$, total molarity: $1 \mathrm{M}$, cerium-concentration: $1 \mathrm{mg} / \mathrm{L}$, U-concentration: $35 \mathrm{~g} / \mathrm{L}$, column inner diameter: $9.7 \mathrm{~mm}$, bed volume: $5.5 \mathrm{~mL}$, adsorber weight: $5.5 \mathrm{~g}$ $\mathrm{MnO}_{2}$, and loading speed: $30 \mathrm{cv} / \mathrm{h}$. Ce-141 was added to the loading solution as a radioactive indicator.

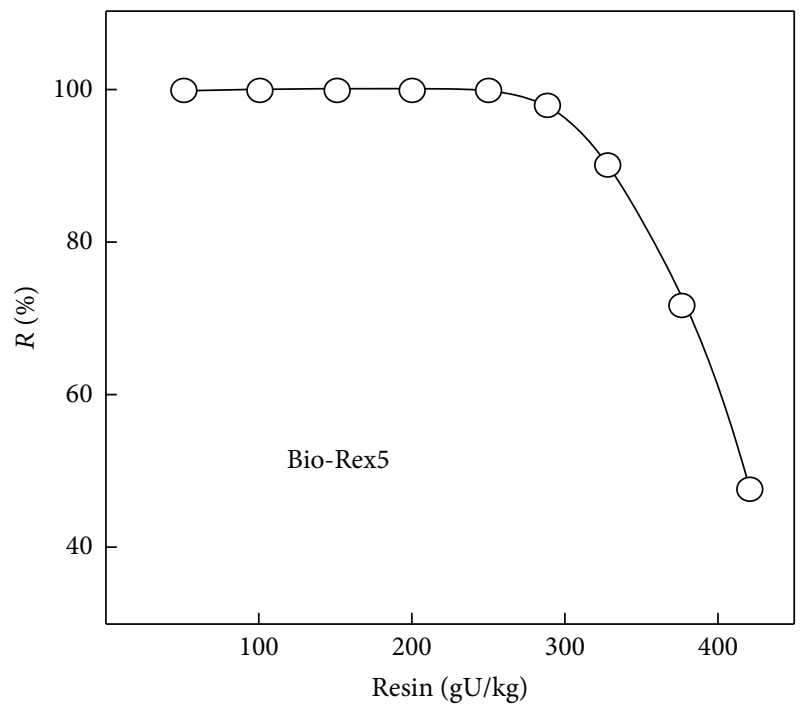

Figure 8: U-loading on Bio-Rex5 U 1: $3 \mathrm{HCO}_{3}{ }^{-} / \mathrm{CO}_{3}{ }^{-2}$.

experienced in different systems, for example, nitric acid. In the latter, 21 species of ruthenium were determined, anionic, neutral, and cationic. The latter is a reason too that the complete separation of ruthenium demands a series of steps.

2.11. Uranium Concentration and Final Purification. The decontaminated fuel solution still has to undergo a final purification process in which the alkaline salt content and the still remaining fission product nuclides are separated. Under such conditions best results are achieved by the proven PUREX-process $[27,28]$. Uranium is extracted from nitric acid solution in tributyl phosphate. Optimal extraction conditions are obtained by the extraction of uranium from approximately $3 \mathrm{M} \mathrm{HNO}_{3}$ in an organic phase containing $30 \mathrm{vol} \%$ TBP in kerosine. The liquid/liquid extraction system

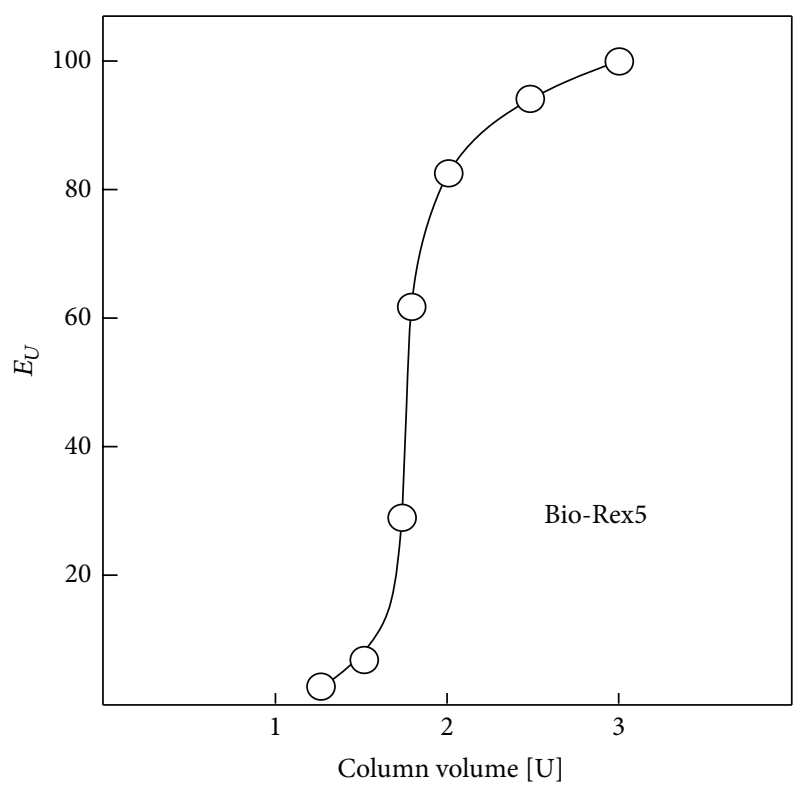

Figure 9: U-elution with $4 \mathrm{M} \mathrm{HNO}_{3}$.

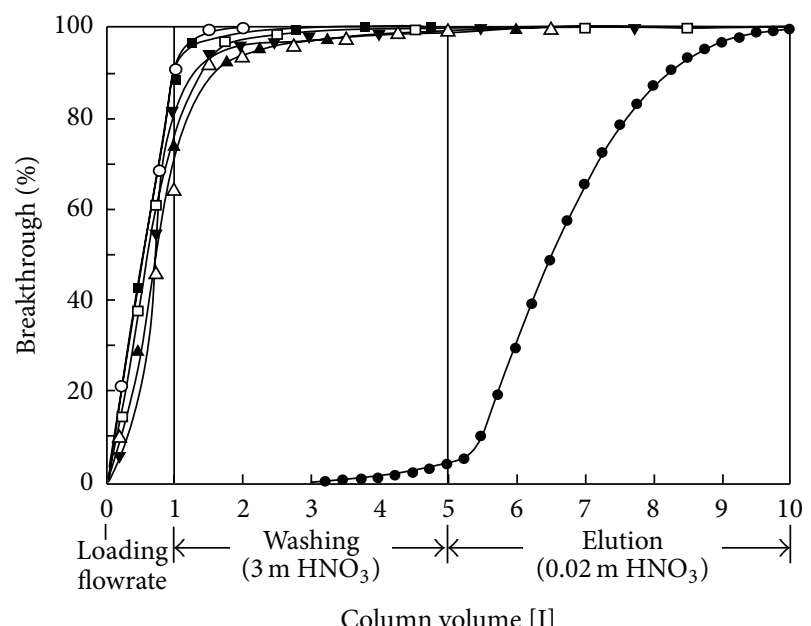

Breakthrough after washing:

Ce-144: $99.4 \%$

- Cs-137: $99.9 \%$

V Nb-95: $99.0 \%$

$\Delta \mathrm{Ru}-106: 99.4 \%$

Zr-95: $99.4 \%$

- Sb-125: $100.0 \%$

- Uran: $3.8 \%$

Figure 10: Decontamination of uranium from fission product species on TBP loaded SM-7 column.

is the best solution for middle to large scale batches and can be operated continuously. The situation is different for the recycling of the U-batches needed for Mo-99 production targets. Batch sizes of 1,000 $\mathrm{g}$ are optimal to be operated in laboratory scale. The most practical operation is achieved by using the solid-bed extraction technique $[29,30]$. It is based on the extraction of $\mathrm{UO}_{2}\left(\mathrm{NO}_{3}\right)_{2}$ dissolved in nitric acid in undiluted TBP. TBP is loaded on a macroporous nonpolar matrix of polystyrene-divinyl benzene such as Bio-Beads SM-2 and SM-4 (Bio-Rad, Richmond, VA, USA) or on the intermediate 


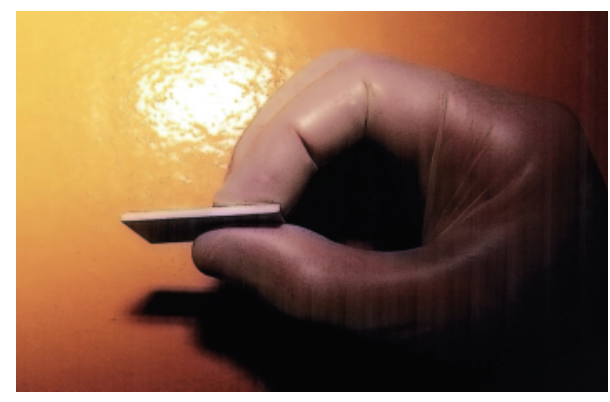

FIGURE 11: Side view of the fuel rectangle.

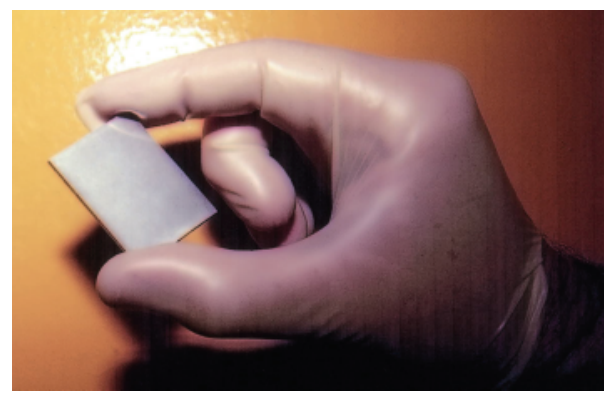

FIGURE 12: Surface view of the fuel rectangle.

polar acrylic ester matrix SM-7 (Bio-Rad). The described technique combines the high decontamination efficiency of the $\mathrm{TBP} / \mathrm{HNO}_{3}$ system with the simple handling of chromatographic operations. Favored operation conditions for the solid bed extraction are achieved from feed solutions of higher U-concentrations. Under such conditions the extraction of contaminants such as ruthenium and zirconium is efficiently reduced. As previously described, the U-solubility in carbonate solutions is limited to $45 \mathrm{gU} / \mathrm{L}$. Optimal decontamination of uranium on TBP loaded solid-bed columns is achieved at U-concentrations in the average of $200 \mathrm{~g} / \mathrm{L}$. Such conditions are realized most practical by loading of the $\mathrm{U}$ tricarbonate species on the intermediate basic exchanger BioRex5 (Bio-Rad) which permits the loading of approx. $300 \mathrm{~g}$ of uranium on $1 \mathrm{~kg}$ of the resin. The elution is carried out by $4 \mathrm{M} \mathrm{HNO}_{3}$ from the bottom to the top of the column to prevent overpressure formation by the released $\mathrm{CO}_{2}$. The eluent acid concentration also presents the optimal loading $\mathrm{HNO}_{3}$ molarity for the solid-bed extraction. Figure 8 shows the U-loading on Bio-Rex 5 from the carbonate solution. Figure 9 shows the U-elution with $4 \mathrm{M} \mathrm{HNO}_{3}$ from the BioRex5. The elution with $4 \mathrm{M} \mathrm{HNO}_{3}$ considers acid losses by adsorption during elution of the exchanger, resulting in an approximate $\mathrm{HNO}_{3}$ molarity of 3 in the U-eluate presenting the optimal molarity for the solid-bed extraction.

Subsequently the U-containing nitric acid solution is fed through the TBP loaded solid-bed column. Uranium is extracted under the optimized loading conditions as a sharp yellow band on the stationary phase while the fission products leave the column at the upper end. After washing the stationary phase with $3 \mathrm{M} \mathrm{HNO}_{3}$, uranium is eluted by $0.02 \mathrm{M}$ $\mathrm{HNO}_{3}$. Figure 10 shows typical solid-bed extraction curves

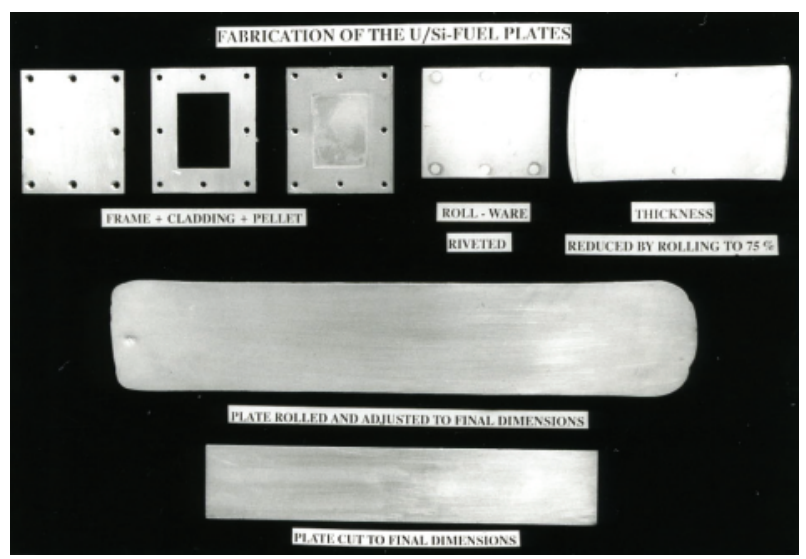

FIgURE 13: Preparation of the uranium silicide target plate.

for uranium and potentially accompanying fission products on a TBP loaded SM7 column.

Uranium is precipitated by ammonium hydroxide. The ammonium diuranate precipitate is centrifuged, dried, and finally calcined at $800^{\circ} \mathrm{C}$ to $\mathrm{U}_{3} \mathrm{O}_{8}$.

2.12. Preparation of the Uranium Silicide Alloy. The uranium oxide is transferred to a nickel crucible and converted to $\mathrm{UF}_{4}$ by treatment with a gas mixture of hydrogen and hydrogen fluoride in argon atmosphere at $650^{\circ} \mathrm{C}$. The reaction is performed in a nickel oven. The $\mathrm{UF}_{4}$-powder is transferred to $\mathrm{KUF}_{5}$ by melting the tetrafluoride with the stoichiometric amount of potassium fluoride in the same oven at $850^{\circ} \mathrm{C}$. The conversion to $\mathrm{KUF}_{5}$ is carried out in argon atmosphere in a graphite crucible. The product is powdered and added in small portions to a melting electrolysis bath of a salt mixture of 50 weight $\% \mathrm{NaCl}$ and $\mathrm{KCl}$ in which the graphite crucible is acting as anode. A molybdenum sheet is used as the cathode. The process is carried out in argon atmosphere at $800^{\circ} \mathrm{C}$. The U-loaded cathode is replaced frequently and washed after subsequent cooling with ethyl-alcohol containing few percent of water and cold water to dissolve the uranium accompanying salt in an ultrasonic bath. The described procedure is carried out in argon atmosphere. The dried U-powder is finally melted in argon atmosphere under low pressure with silicon to $\mathrm{U}_{3} \mathrm{Si}_{2}$. The melting procedure is carried out in a high-frequency oven at $1,850^{\circ} \mathrm{C}$.

2.13. Fuel Targeting. The alloy is transferred into a glove box line in which the $\mathrm{U}_{3} \mathrm{Si}_{2}$ is grounded in a hard metal swinging mill. All following operations up to the fuel meat encapsulation are carried out in argon atmosphere. The milled alloy is sieved. Only particles with grain sizes below 40 micrometers were mixed with aluminum powder of the same particle size. Aliquots of this mixture are pressed to rectangles which will present the meat zone in the final plate. Figures 11 and 12 show photographs of formed rectangles from 2 directions. Figure 13 shows the target preparation steps starting by the formed rectangle. 


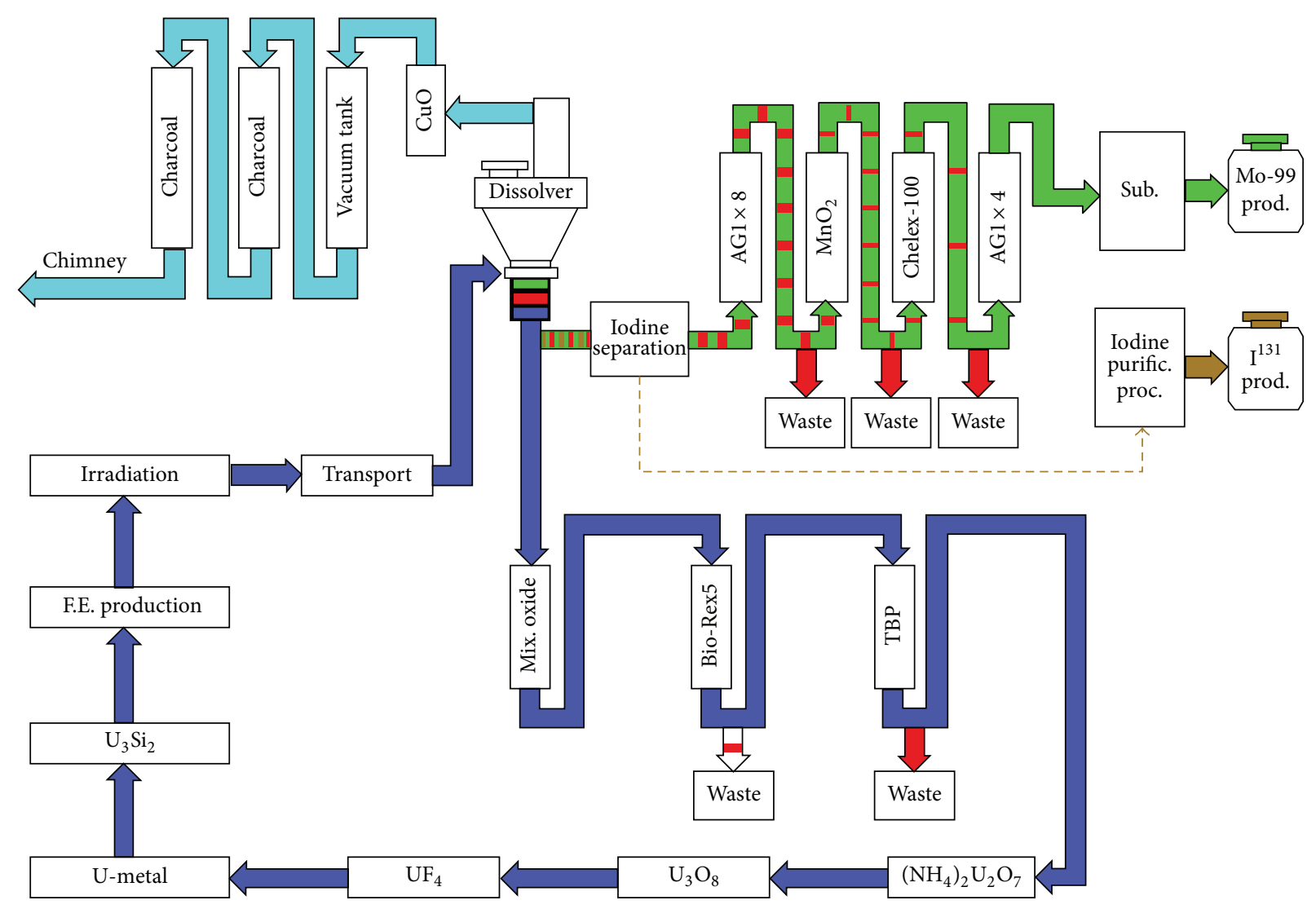

FIGURE 14: Simplified scheme of the $\mathrm{U}_{3} \mathrm{Si}_{2}$ production cycle.

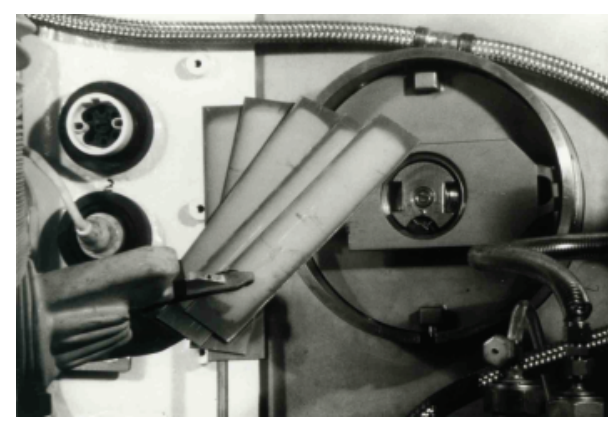

FIGURE 15: Irradiated silicide-based fuel targets prior to starting the dissolution process at KFK.

Each rectangle (meat) is placed into a suitable frame of an aluminum-magnesium alloy, for example, AlMgl. Then the combined frame + meat is covered on both sides with plates of the same alloy. The package is riveted together and stepwise rolled to the final thickness. Before each rolling step the fuel package is heated up to $400-450^{\circ} \mathrm{C}$ before each rolling step. The fuel zone is marked under an X-ray screen. After cutting to the final shape, surface treatment completes the manufacturing. Figure 13 depicts the parts and steps of target manufacturing. The manufacturing technology follows related experiences at KFK [31, 32].

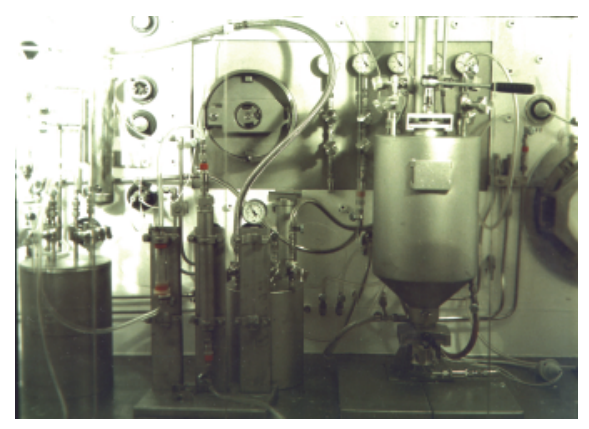

FIGURE 16: Dissolution cell and the applied hardware devices for process operation at KFK.

2.14. Target Irradiation and Processing. Hundreds of targets were produced from natural uranium in order to develop and verify production technique and fulfillment of the required quality standards. The target qualification standards were identical to those of regular MTR-fuel elements qualification standards.

Fuel densities were varying between 1.5 and $5.0 \mathrm{gU} / \mathrm{cm}^{3}$. Natural uranium targets were also used for the development and cold testing of the new silicide treatment process. The uranium precipitates generated by cold testing have been recycled. The prepared silicide fuel was applied for the 

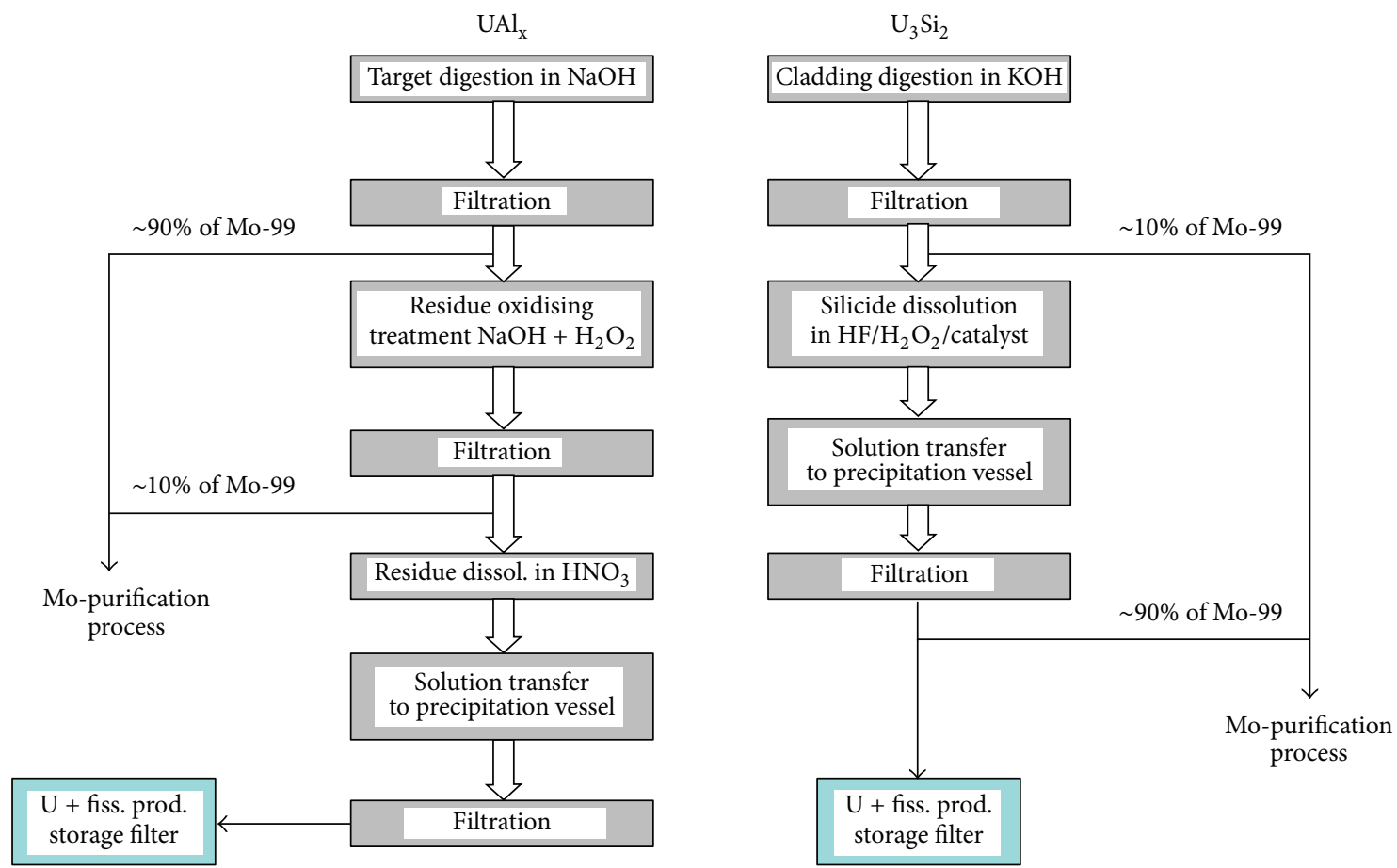

FIGURE 17: Fission Mo-99 production flow sheets for irradiated $\mathrm{UAl}_{x}$ and $\mathrm{U}_{3} \mathrm{Si}_{2}$ fueled targets.

preparation of new targets again and had to undergo the fuel qualification needed for irradiation. The qualified targets were again dissolved without being irradiated. The material was repeatedly recycled and processed.

The achieved experience was applied for the preparation of those LEU targets foreseen for irradiation and hot process demonstration. The produced LEU targets comprised varying densities up to $5.0 \mathrm{gU} / \mathrm{cm}^{3}$. The U-densities of all irradiated targets were $3 \mathrm{gU} / \mathrm{cm}^{3}$. The uranium enrichment of the targets was $19.75 \%$. It was adjusted by blending of recycled HEU fuel of $91 \%$ enrichment with natural uranium. The blending was carried out by adding of a solution of uranyl nitrate of the natural uranium to a part of the uranium eluate of the TBP solid-bed column at the end of purification cycle. The mixture was precipitated as ammonium diuranate and further treated up to metal as described.

The silicide production cycle of Figure 14 was completed by demonstration tests at KFK, operated at 1,000 Ci of Mo99 at EOP. Figure 15 shows 5 of the used irradiated silicide fuel targets prior to starting the dissolution process. Figure 16 shows the applied dissolution cell and major components of the hardware devices applied for the hot demonstration operations.

The hot experiments with $\mathrm{U}_{3} \mathrm{Si}_{2}$-based targets showed, except the dissolution and the related off-gas handling operations, no difference to the processing of the $\mathrm{UAl}_{x}$-based fuels. The latter were frequently operated on similar scale for over 100 production runs. The dissolution tests of the silicide targets showed no difference in solubility between irradiated and nonirradiated silicide nor with fuel densities varying from 1.5 to $5.0 \mathrm{gU} / \mathrm{cm}^{3}$. The achieved results were not surprising, as in extensive cold dissolution experiments pure silicide grains of several millimeters diameter were smoothly dissolved in the developed system.

\section{Conclusions}

The described experiments and related high-active demonstrations underlined the advantage of uranium silicide fuels as an outstanding target material for the production of fission Mo-99. Silicide targets combine remarkable features predestinating them as starting up materials for the large scale production of fission nuclides when starting from LEU. Among others these features are as follows.

(i) The full compensation of the enrichment drop from HEU to LEU in the production targets.

(ii) Long term proven excellent behavior in irradiation as MTR-fuel, which simplifies their acceptance in all involved research reactors supplementary.

(iii) Qualification on large scale and to high burn-ups as nuclear fuels up to uranium densities of $5.8 \mathrm{gU} / \mathrm{cm}^{3}$ which even permits outstanding recycling potential for the generated spent fuel.

(iv) Reliable and reproducible production quality, which can be easily supervised with view to settled standards.

(v) Contamination and off-gas free handling before starting up the chemical process regarding the fact that no mechanical target dismantling is needed.

The demonstrated process for the production of fission Mo-99 and the integrated fuel cycle, both as described, is 
designed for the long-term large scale operation. Relevant features are as follows.

(i) Complete separation of the nuclear fuel from the Mostream, already at the beginning of the separation process, combined with the quantitative retention and the safe enclosure of the nuclear fuel together with the bulk of fission products.

(ii) Exceptional low environmental impact comparable to that $\mathrm{UAl}_{x}$ process operating on full scale at Petten, The Netherlands.

(iii) Uncomplicated and economical to handle, noncorrosive, and nuclear fuel free alkaline waste.

(iv) Reliable immobilization of the fluoride content in the alkaline waste by formation of calcium fluoride during solidification, $\mathrm{CaF}_{2}$ being a mineral "fluorite" of very low solubility.

(v) Efficiently reduced nuclear waste amounts by recycling and retargeting of the spent fuel.

(vi) Shorter operation times for the silicide fuel in comparison to the processing of similar fuel amounts of $\mathrm{UAl}_{x}$. Figure 17 shows the operations needed for both fuel target types and demonstrates the related processing schemes for $\mathrm{UAl}_{x}$ and $\mathrm{U}_{3} \mathrm{Si}_{2}$. In case of the $\mathrm{UAl}_{x}$ processing, the needed final treatment for safe spent fuel enclosure as diuranate is an additional operation but integral part of the silicide processing already.

\section{Acknowledgment}

For the preparation of this paper the authour was substantially supported by H.-J. Roegler, consulted about all matters of research reactors and their utilization.

\section{References}

[1] C. J. Fallias, A. More de Westgaver, L. Heeren, J. M. Baugnet, J. M. Gandoflo, and W. Boeykens, "Production of radioisotopes with BR2 facilities," in Proceedings of the BR-2 Reactor Meeting, INIS MF 4426, pp. 1-11, Mol, Belgium, 1978.

[2] R. O. Marques, P. R. Cristini, H. Fernandez, and D. Marziale, "Operation and installation for fission for fission ${ }^{99}$ Mo production in Argentina. Fission molybdenum for medical use," in Proceedings of the Technical Committee Meeting Organized by the International Atomic Energy Agency, IAEA-TECDOC-515, pp. 23-33, Karlsruhe, Germany, October 1987.

[3] J. Salacz, "Processing of irradiated ${ }^{235} \mathrm{U}$ for the production of ${ }^{99} \mathrm{Mo},{ }^{131} \mathrm{I}$, and ${ }^{133}$ Xe radioisotopes. Fission molybdenum for medical use," in Proceedings of the Technical Committee Meeting Organized by the International Atomic Energy Agency, IAEATECDOC-515, pp. 149-154, Karlsruhe, Germany, October 1987.

[4] A. A. Sameh and H. J. Ache, "Production techinques of fission molybdenum-99," Radiochimica Acta, vol. 41, pp. 65-72, 1987.

[5] A. Mushtaq, "Specifications and qualification of uranium/aluminum alloy plate target for the production of fission molybdenum-99," Nuclear Engineering and Design, vol. 241, no. 1, pp. 163-167, 2011.
[6] K. L. Ali, A. A. Khan, A. Mushtaq et al., "Development of low enriched uranium target plates by thermo-mechanical processing of UAl2-Al matrix for production of ${ }^{99}$ Mo in Pakistan," Nuclear Engineering and Design, vol. 255, pp. 77-85, 2013.

[7] G. Ball, "Status update on the ${ }^{99}$ Mo HEU/LEU conversion in South Africa," in Proceedings of the NNSA 2nd Mo-99 Topical Meeting on Molybdenum-99 Technological Development, Chicago, Ill, USA, April 2013.

[8] M. Druce, "Manufactoring Mo-99 from LEU for Australian market," in Proceedings of the NNSA 2nd Mo-99 Topical Meeting on Molybdenum-99 Technological Development, Chicago, Ill, USA, April 2013.

[9] G. F. Vandegrift, J. L. Snelgrove, S. Aase, M. M. Bretschner, and B. A. Buchholz, "Converting targets and process for fissionproduct ${ }^{99}$ Mo from high to low enriched uranium," IAEA TECODOC, 1997.

[10] J. Jerden, J. Baily, L. Hafenrichter, and G. F. Vandegrift, "Fullscale testing of the ambient pressure,acid-dissolution frontend process for the current Mo-99 recovery process," Chemical Science and Engineering. In press.

[11] A. Guelis, G. Vandegrift, and S. Wiedmeyer, "Uranium anodic dissolution under slightly alkaline conditions," ANL Progress Report, Argonne, 2012.

[12] J. D. Kwok, G .F. Vandegrift, and J. E. Matos, "Processing of low-burnup LEU silicide targets," in Processedings of the 1988 International Meeting on Reduced Enrichment for Research and Test Reactors, ANL/RERTR/TM-13, CONF-880221, pp. 434442, San Diego, Calif, USA, 1993.

[13] Cols, P. R. Cristini, and R. O. Marques, "Preliminary investigations on the use of uranium silicide targets for fission Mo-99 production," in Proceedings of the 1994 International Meeting on Reduced Enrichment for Research and Test Reactors, ANL/RERTR/TM-20, Williamsburg, Va, USA, September 1994.

[14] G. F. Vandegrift, A. V. Gelis, S. B. Aase, A. J. Bakel, E. Freiberg Y Koma, and C. Conner, "ANL progress in developing a target and process for converting CNEA Mo-99 production to lowenriched uranium," in Proceedings of the 2002 International Meeting on Reduced Enrichment for Research and Test Reactors, San Carlos de Bariloche, Argentina, November 2002.

[15] J. P. Durand, Y. Fanjas, and A. Tissier, "Development of higherdensity fuel at CERCA status as of Oct.1992," in Proceedings of the 1992 International Meeting on Reduced Enrichment for Research and Test Reactors-Status, Roskilde, Denmark, September-October 1992, Argonne National Laboratory Report ANL/RERTR/TM-19, CONF-9209266.

[16] A. A. Sameh and A. Bertram-Berg, "HEU and LEU MTR fuel elements as target materials for the production of fission molybdenum," in Proceedings of the 1992 International Meeting on Reduced Enrichment for Research and Test Reactors, Roskilde, Denmark, September-October 1992, Argonne National Laboratory Report.

[17] J. P. Durand, J. C. Cottone, M. Mahe, and G. Ferraz, "LEU fuel development at CERCA-status as of October 1998," in Proceedings of the 1998 International Meeting on Reduced Enrichment for Research and Test Reactors, Sao Paulo, Brazil, October 1998, Argonne National Laboratory Report.

[18] A. A. Sameh, "Production of fission Mo-99 from LEU uranium silicide target materials," in Proceedings of the 2000 Symposium on Isotope and Radiation Applications, Institute of Nuclear Energy Research, Lung-Tan, Taiwan, May 2000. 
[19] J. L. Snelgrove, Qualification Status of 6-GU/Cm3 U3Si2 Dispersion Targets for $99 \mathrm{Mo}$ Production, Argonne National Laboratory, 2011.

[20] Workshop on Signatures of Medical and Industrial Isotope Production (WOSMIP '09), Friuli-Venezia Giulia, Italy, July 2009, PNNL-19294.

[21] A. A. Sameh, "KIT Process operating at Petten-the Netherlands," in Proceedings of the Workshop on Signatures of Medical and Industrial Isotope Production (WOSMIP '10), Friuli-Venezia Giulia, Italy, June 2010, PNNL-21052.

[22] A. A. Sameh and A. Bertram-Berg, "Process for treating dissolution residues," Patent DE4241955, US5419881,1995.

[23] A. A. Sameh, "Processing and off gas handling of irradiated LEU uranium silicide," in Proceedings of the Workshop on Signatures of Medical and Industrial Isotope Production (WOSMIP '11), Friuli-Venezia Giulia, Italy, June 2011.

[24] A. A. Sameh and W. Leifeld, "Process for separation of molybdenum," Patent DE4231955, USA 5.508.010, 1996.

[25] A. A. Sameh, J. Hoogveldt, and J. Reinhardt, "Process for recovering molybdenum-99 from a matrix containing neutron irradiated fissionable materials and fission products," Patent DE 2758783, 1994.

[26] A. A. Sameh and J. Haag, "Process for the separation of large amounts of uranium from small amounts of radioactive fission products, which are present in basic, aqueous carbonate containing solutions," Patent DE3428877, USA 4696768, 1987.

[27] R. G. Wymer and B. L. Vondra, Light Water Reactor Fuel Cycle, CRC Press, Boca Raton, Fla, USA, 1981.

[28] H.-J. Bleyl, D. Ertel, H. Goldacker, G. Petrich, J. Romer, and H. Schmieder, "Recent experimental findings on the way to the one-cycle Purex process," Kerntechnik, vol. 55, no. 1, pp. 21-26, 1990.

[29] R. Kröbel and A. Maier, International Solvent Extraction Conference, Lyon, France, 1974.

[30] H. Eschrich and W. Ochsenfeld, "Application of extraction chromatography to nuclear fuel reprocessing," Separation Science and Technology, vol. 15, no. 4, pp. 697-732, 1980.

[31] S. Nazare, G. Ondracek, and F. Thümler, "UAl3-Al als Dispersionsbrennstoff für Höchstflussreaktoren," KFK, 1252, 1970.

[32] S. Nazare, Private communication and advice on silicide preparation and targeting (1988-1990). 


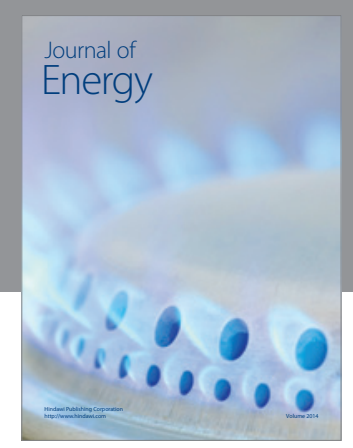

Journal of

Industrial Engineering
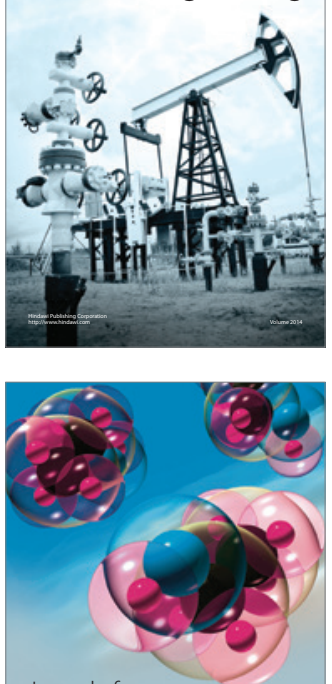

Fuels
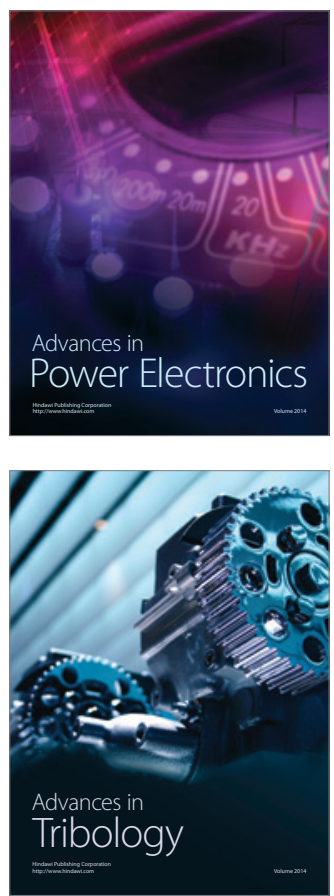

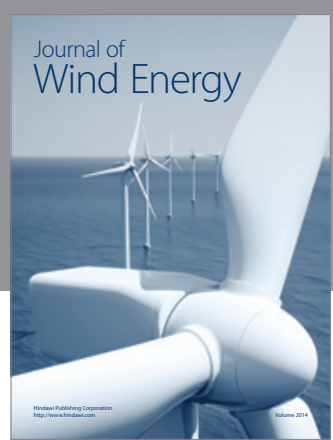

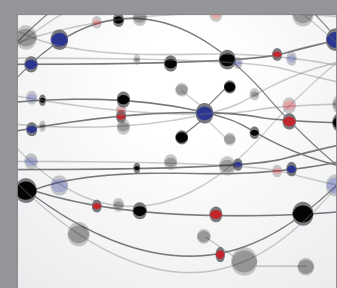

The Scientific World Journal

Submit your manuscripts at http://www.hindawi.com

Journal of

Structures
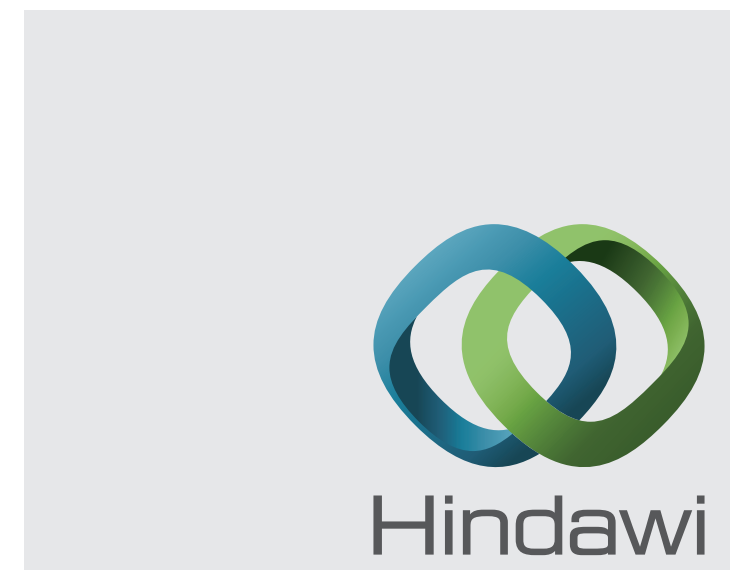

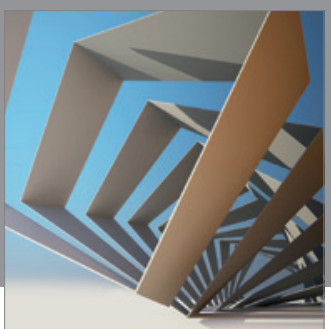

Rotating

Machinery
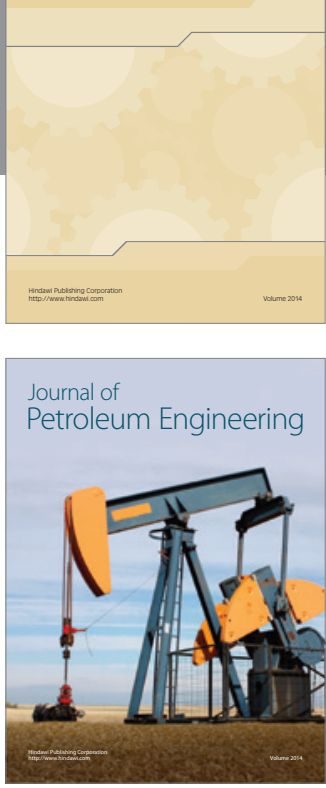

Journal of

Solar Energy
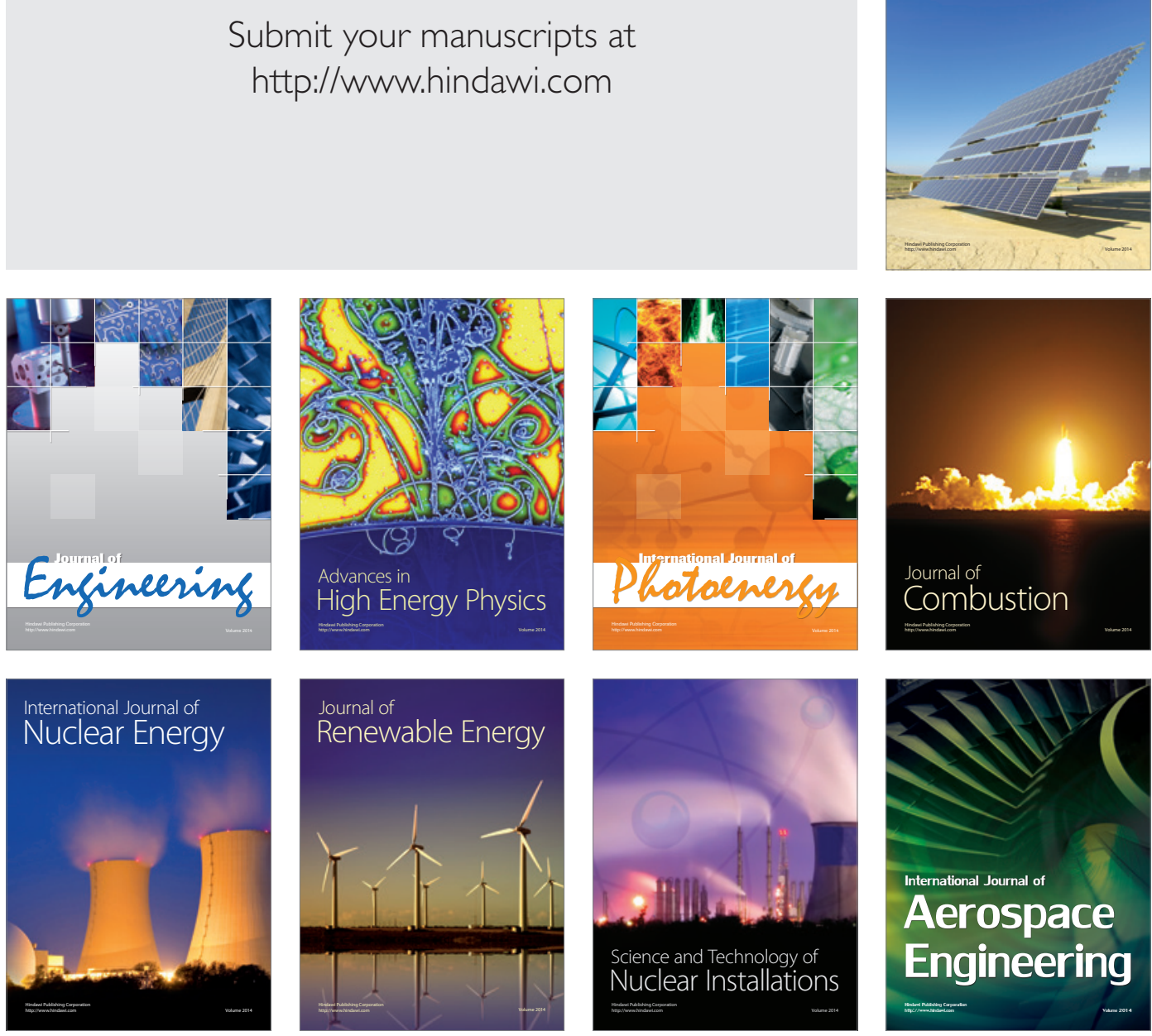